\title{
The Influence of Psychological Intervention on Cognitive Appraisal and Level of Anxiety in Dialysis Patients: A Pilot Study
}

\author{
K. Bargiel-Matusiewicz, ${ }^{1, *}$ A. Trzcieniecka-Green ${ }^{2}$ and A. Kozłowska ${ }^{3}$ \\ ${ }^{1}$ Faculty of Psychology, University of Warsaw, Poland \\ ${ }^{2}$ Department of Psychology, Medical University of Silesia, Poland \\ ${ }^{3}$ Faculty of Psychology, University of Warsaw, Poland
}

\begin{abstract}
Objective: The great progress with the application of a dialysis allows patients with the end-stage renal disease to live in a satisfactory somatic state for many years. This pilot study examined if the psychological intervention improves psychic state of the patients with renal disease undergoing hemodyalisis.

Methods: The study was a randomized controlled trial using a convenience sample of 62 fully informed and consenting patients with the end-stage renal disease who were assigned to experimental (psychological intervention) or control (usual care) groups. Participants in the experimental group listened to a CD with a psychological intervention twice a day during 3 weeks. The instruments were the Cognitive Appraisal Inventory and the STAI-Anxiety Inventory.

Results: After the application of a psychological intervention, the experimental group had a lower level of anxiety $\mathrm{t}(30)=$ $2.99 ; \mathrm{p}<.005$, a weaker intensity of cognitive appraisal of the treatment situation as a threat $\mathrm{t}(30)=3.48 ; \mathrm{p}<.05$, a weaker intensity of cognitive appraisal of the situation as a harm/loss $t(30)=2.75 ; p<.05$ and a stronger intensity of cognitive appraisal of the situation as a challenge $\mathrm{t}(30)=3.49 ; \mathrm{p}<.05$. The applied psychological intervention makes it possible to decrease the level of anxiety and to change cognitive appraisal of treatment situation.

Conclusions: The applied psychological intervention influences the patients' psychological state in a positive way. Such changes may indirectly contribute to improving social contacts as well as to increasing satisfaction with the undertaken activities.
\end{abstract}

Keywords: Psychological intervention, anxiety, cognitive appraisal, dialysis patients.

\section{INTRODUCTION}

This article aims at presenting a psychological intervention applied in a group of dialysis patients to evaluate and change their cognitive appraisal of the situation and to decrease the level of their anxiety. Both aspects have a great importance from the perspective of a health prognosis in this group of patients.

The patients who suffer from the end-stage renal disease comprise a very specific group. Their life as they know it undergoes a radical change. The necessity to observe a diet and to control the amounts of the intake of fluids emerges. In the case of dialysis patients, the necessity to visit the dialysis station about three times a week for a few hours at a time becomes burdensome, too [1-3]. The psychological problems which accompany dialysis treatments have many aspects worth noting.

The first aspect is a lowered mood and a resignation attitude. The symptoms which usually occur in depression take on a particular importance in dialysis patients [4]. Loss of appetite in these patients may lead to deepening the

\footnotetext{
*Address correspondence to this author at the Faculty of Psychology, University of Warsaw, 5/7 Stawki St, 00-183 Warsaw, Poland; Tel: +48 22 5549769; Fax: +48 2255497 03; E-mail: kmatusiewicz@psych.uw.edu.pl
}

already existing metabolic disturbances. Lack of motivation and weakening may lead to neglecting doctor's guidelines. G. Brownbridge and D. Fielding [5] have shown a very important dependence of the most important indicators of a somatic condition in dialysis patients (the level of potassium, blood pressure, the level of urea, putting on weight between dialyses, etc., among others) on psychosocial factors, in particular on the level of depressiveness and anxiety. Depressive symptoms may predict the future risk of developing severe bodily pain in dialysis patients [6].

A fall in one's mood may even lead to abandoning the treatment. The E. McDade-Montez's [7] research showed that, within the period of up to 4 years since the occurrence of the symptoms of depression, $18 \%$ of patients gave up on the dialyses.

The fact that the dialysis patients have fallen ill is not the only source of their anxiety. Such factors as advanced technical medical procedures and lack of knowledge of how individual life and health saving equipment and machines operate are another source of anxiety in these patients [8]. Hence, possibilities of psychological support are worth considering in the case of dialysis patients.

The conducted empirical research on the quality of life in somatically ill patients shows that the earliest possible psy- 
chological intervention is very helpful [9]. Cardiological and oncological patients undergo psychological interventions most often [10]. So far, dialysis patients have received such help on rare occasions [11]. This research analyses the influence of a psychological intervention on the cognitive appraisal of the situation and the level of anxiety.

\section{MATERIAL}

As mentioned earlier, the patients' expectations regarding their future lives, including possibilities and limitations, have a marked importance for their functioning. The process of appraising individual situations is an indispensable element of a daily life. Those aspects of a situation are taken into consideration which are crucial from the standpoint of a broadly understood feeling of well-being. Thus, it is not only the objective properties of a situation that decide about the intensity of the stress one experiences but also the way the person perceives the situation, i.e. subjective factors [12]. Categorizing an event is possible thanks to the existence of patterns shaped as a result of the experience, among others. Appraising a situation as stressful may be done in three categories: harm/loss (when some values are lost); threat (when a loss of values is anticipated) and a challenge (if the subject assumes a possibility of meeting the expectations of the surroundings).

The STAI-Anxiety Inventory was used to measure anxiety and the Cognitive Appraisal Inventory was used for the cognitive appraisal. The tools are discussed in the next part of the article.

The inventory for measuring anxiety as a state and as a trait (State-Trait Anxiety Inventory-STAI) was developed by Spielberger et al. [13]. This method is self-descriptive and consists of two separate, 20-item scales, the first one $(\mathrm{X}-1)$ is intended for measuring anxiety as a state and the other (X-2) for measuring anxiety as a feature. In this research, we used the scale of measuring anxiety as a state $(\mathrm{X}-1)$.

The Cognitive Appraisal Inventory consists of 33 statements to which answers are given on a four-grade scale. The questionnaire consists of three subscales: threat, harm/loss, and a challenge [1, 12]. Both of the applied tools have satisfactory psychometric characteristics.

\section{THE SUBJECTS}

72 persons participated in the first phase and 62 persons participated in the second phase of the study. The following is the characteristic of the studied group.

The men comprised $54.2 \%$ of the subjects and women comprised $45.8 \%$. The average age was 50.17 years with a standard deviation of 11.76 years. The youngest participant in the study was 22 years old and the oldest was 75 . The highest number of subjects were high school graduates $(40.28 \%)$, and the second largest group had vocational education $(27.78 \%)$. The persons with tertiary education comprised $18.06 \%$ of the studied group, while the remaining persons had primary education $(8.33 \%)$ or a bachelor's degree $(5.56 \%)$. The subjects most often declared (72.22\%) that they live in a steady relationship. Only $11.11 \%$ persons were single. Less than $3 \%$ were in separation, and over $5.5 \%$ were divorced. Over $8.3 \%$ of the participants were widowed.

\section{METHODS}

The study was approved by an institutional Ethics Committee.

\section{Description of the Intervention:}

Between 2007-2008, a psychological intervention was verified, in which the patients listened to a $C D$ with a recorded psychological intervention twice a day for a period of three weeks. The duration of the recording was twenty minutes.

The presented intervention is based on the principles of the Ericksonian therapy [14] and includes the following therapeutic metaphors:

- The birds that experience freedom and, in a bad weather, they look for a temporary shelter.

Many dialyzed persons lead a daily life in the way that is very close to a regular life style in the community they function normally. They work (more often part time), they have spouses and children. The research shows, however, that their feeling of limited freedom connected with the necessity of spending about 5 hours three times a week at a dialysis station has an adverse impact on their level of satisfaction with their lives.

The feeling of limitation as regards controlling their own time often makes them resign from many activities which, with appropriate motivation and attitude, they could do. The metaphor of the birds which during rain and a storm must seek shelter in a safe place to enjoy freedom in good weather again is an analogy to the dialysis therapy. The aim of the metaphor is to make the dialyzed persons become aware of the value of freedom and the latitude they have in between dialyses. By way of referring to natural phenomena, the analogy of the rain and the birds hiding from it may also make the situation of going through the dialysis therapy more neutral in its reception.

\section{- A Found Treasure}

This metaphor is to make the patients aware of everyday values, little pleasures, hence to increase the intensity of experiencing positive emotions.

- People Taking a Walk in the Park

This image and the suggestion of recalling warm-hearted and nice people aims at increasing the awareness of sources of social support one already has.

The subjects were divided into two groups of the same number of participants: a control group (with no psychological intervention applied) and an experimental group (subjected to a psychological intervention). The study had a prospective character and was carried out in a natural environment. The dialyzed patients were randomly assigned to the control or experimental group and filled a set of questionnaires during researchers' first visit. During the 3 weeks between the researchers' visits, they listened to the recordings with the psychological intervention.

\section{RESULTS AND STATISTICS}

As mentioned earlier, the study included the differences between anxiety and cognitive appraisal. The results of the 
measurement before and after the psychological intervention were compared. Because the distribution of the analyzed variables was concordant with the normal distribution, parametric tests were applied.

Table 1 presents the difference at the anxiety level before and after the application of a psychological intervention. Statistics $t$ was 2.99 at the significance level $\mathrm{p}<.005$. Therefore, it can be stated that the anxiety level dropped significantly.

Table 1 depicts also the difference in the intensification of cognitive appraisal as a challenge before and after application of the psychological intervention. Statistics $t$ was 3.49 at the level of significance $\mathrm{p}<.05$. Therefore, it can be stated that the intensity of the perception of a challenging situation increased significantly.

The table shows the difference in the intensification of cognitive appraisal as threat before and after a psychological intervention. Statistics $t$ was 3.48 at the level of significance $p<.05$. We can say, then, that the intensification of the perception of a situation as danger decreased significantly.

Table 1 shows also the difference in intensification of cognitive appraisal as harm/loss before and after the application of the psychological intervention. Statistics $t$ was 2.75 at the significance level $\mathrm{p}<.05$. Therefore, we can say that the intensification of the perception as harm/loss decreased significantly. No significant statistical differences between the first and the second measurement of the analyzed variables were noted in the control group.

\section{DISCUSSION}

Based on the presented study, we can say that the applied psychological intervention had a positive influence on the perception of the patients' health situation. The patients evaluated their situation more often as a challenge and less often as a threat and harm/loss.

The intervention also had a positive impact on the patients' emotional state through lowering the level of their anxiety. The positive impact of psychological influence on the dialysis patients was also noted by researchers from Taiwan [11].

The changes in the scope of the cognitive appraisal seem to have a great importance in the process of dealing with the difficulties. The perception of a situation as a challenge can have a very positive impact on the patient's behavior and coping with the illness. For such a patient, the illness becomes an obstacle, something that must be overcome by way of available resources. Everything that can lead to success and decrease anxiety becomes important. Increasing the intensity of perception in dialysis therapy in the category of a challenge can foster constructive coping with stress, increase patients' motivation to follow physician's guidelines, thereby have an advantageous influence on the prognosis of their health.

This is especially important in the group of dialysis patients as, so far, the research shows that they fail to follow their recommended diet periodically, therefore it is important to increase the patients' motivation for treatment [2]. The most extreme lack of adjustment to the situation is refusal of treatment, i.e. stopping the dialysis therapy altogether, which can even lead to death [4, 7]. It is also worth to mention that part of the psychological abnormalities may also be due to coenzyme Q10 deficiency which is common among patients with renal failure [15].

The studies conducted by L. Timmer's team [3] also confirm the importance of cognitive evaluation of the illness. The researchers showed that the perception of the illness in the dialyzed patients explains between 17 and $51 \%$ of variance of the experienced quality of life.

Under the dominating view on co-variation of cognition and emotions one can predict that the influence on the cognitive sphere may result in benefits in the emotional sphere and vice versa. From the Lazarus' paradigm [12] follows an assumption of the cognitive appraisal influence upon emotions; however, contemporary studies indicate co-variation of emotions and cognition. Parrot and Sabini [16] confirm that, indeed, the mechanism of cognitive appraisal is not purely cognitive. It is saturated with evaluative elements to a smaller or higher degree.

Nowadays, many authors stress the importance of a patient's emotional state. Experiencing positive emotions is of a great importance in better coping with stress [7] and to broaden the scope of attention, cognition and action as well as to increase physical, intellectual and social resources [17].

S. Folkman and J. Moskowitz [18] also note the important role of positive emotions in adaptive coping, especially in the conditions of long-lasting stress. It is interesting, therefore, to look for factors which allow a positive reappraisal and experiencing positive emotions. Such a search

Table 1. Comparison of the Variables Before and after the Psychological Intervention

\begin{tabular}{|c|c|c|c|c|c|c|c|}
\hline \multicolumn{3}{|c|}{ Time 1} & \multicolumn{2}{|c|}{ Time 2} & $\mathbf{N}$ & df & Statistics \\
\hline challenge & 31.32 & 3.04 & 33.24 & 3.06 & 31 & 30 & $3.49 \quad(*)$ \\
\hline threat & 23.64 & 2.61 & 21.81 & 2.58 & 31 & 30 & $3.48 \quad(*)$ \\
\hline
\end{tabular}

$* \mathrm{p}<0.05$ 
can manifest itself in the application of a psychological intervention. L. Timmers [3] expresses the view that the interventions which are focused on coping with the illness and its consequences can improve the quality of life in dialysis patients.

The interventions the authors describe in this article can constitute one of many forms of affecting the frame of mind in dialysis patients as they contribute to its improvement.

\section{ACKNOWLEDGEMENTS}

This project was realized at The Faculty of Psychology, University of Warsaw in cooperation with The Department of Psychology, Medical University of Silesia and was supported by The Polish Ministry of Science and Higher Education.

\section{CONFLICTS OF INTEREST}

The authors declared no conflicts of interest in relation to this article.

\section{REFERENCES}

[1] Bargiel-Matusiewicz K. Psychological influence on the psychical state of hemodialysis patients. J Physiol Pharmacol 2005; 57: 33-8.

[2] Barnett T, Li Yoong T, Pinikahana J, Si-Yen T. Fluid compliance among patients having hemodialysis: Can an educational programme make a difference? J Adv Nurs 2008; 61: 300-6.

[3] Timmers L, Thong M, Dekker FW, et al. Illness perception in dialysis patients and their association with quality of life. Psychology Health 2008; 23: 679-90.

[4] Everest KD, Brantley J, Sletten C, Jones GN, McKnight GT. The relation of stress and depression to interdialytic weight gain in hemodialysis patients. Behav Med 1995; 21: 25-30.
[5] Brownbridge G, Fielding DM. Psychosocial adjustment and adherence to dialysis treatment regimes. Pediatr Nephrol 1994; 8: 744-9.

[6] Yamamoto Y, Hayashino Y, Akiba T, et al. Depressive symptoms predict the subsequent risk of bodily pain in dialysis patients: Japan dialysis outcomes and practice patterns study. Pain Med 2009; 10: 883-9.

[7] McDade-Montez EA, Christensen AJ, Cvengros JA. The role of depression symptoms in dialysis withdrawal. Health Psychol 2006; 25: $198-204$

[8] Welch JL, Austin JK. Stressors, coping and depression in hemodialysis patients. J Adv Nurs 2001; 33: 200-7.

[9] Cosette S, Frasure-Smith N, Lesperance F. Clinical implications of a reduction in psychological distress on cardiac prognosis in patients participating in a psychosocial intervention program. Psychosom Med 2001; 63: 257-66.

[10] Linden W, Stossel C, Maurice J. Psychosocial interventions for patients with coronary artery disease: a meta- analysis. Arch Intern Med 1996; 156: 745-52.

[11] Tsay SL, Lee YC, Lee YC. Effects of an adaptation training programme for patients with end-stage renal disease. J Adv Nurs 2005; 50: 39-46.

[12] Lazarus RS. From psychological stress to the emotions: A history of changing outlooks. Annu Rev Psychol 1993; 44: 1-21.

[13] Spielberger CD. Manual for the State -Trait Anxiety Inventory. Palo Alto, California, Consulting Psychologists Press 1983.

[14] Erickson BA. Ericksonian therapy demystified: A straightforward approach. In: Zeig JK, Ed. Ericksonian methods: The essence of the story. pp. 147-162. Brunner/Mazel: Philadelphia 1994.

[15] Singh RB, Khanna HK, Niaz MA. Randomized, double blind, placebo controlled trial of coenzyme Q10 in chronic renal failure; discovery of a new role. J Nutr Environ Med 2001; 11: 43-51.

[16] Parrot WG, Sabini J. On the emotional qualities of certain types of cognition: A reply to arguments for the independence of cognition and affect. Cognit Ther Res 1989; 13: 49-65.

[17] Fredrickson BL. What good are positive emotions? Rev Gen Psychol 1998; 2: 300-19.

[18] Folkman S, Moskowitz JT. Coping: Pitfalls and promise. Annu Rev Psychol 2004; 55: 745-74. 